\title{
Calcium Influx and Protein Phosphorylation Mediate the Metabolic Stabilization of Synaptic Acetylcholine Receptors in Muscle
}

\author{
P. Caroni, ${ }^{1}$ S. Rotzler, ${ }^{2}$ J. C. Britt, ${ }^{2}$ and H. R. Brenner ${ }^{2}$ \\ 'Friedrich Miescher Institute, 4002 Basel, Switzerland and 'Department of Physiology, University of Basel, 4051 Basel, \\ Switzerland
}

During neuromuscular synapse development, the degradation rate of $\mathrm{ACh}$ receptors (AChRs) accumulated in the synaptic portion of the muscle membrane is drastically reduced under neural control, their half-life $t_{1 / 2}$ increasing from $1 \mathrm{~d}$ to about $12 \mathrm{~d}$. Recent evidence suggests that the metabolic stability of synaptic AChRs is mediated by the muscle activity induced by the nerve. We have now investigated the pathway linking muscle activity and metabolic stabilization of synaptic AChRs in organ cultured rat muscle. Soleus and diaphragm muscles were denervated for 14-40 d, a procedure leading to the destabilization of synaptic AChRs, and conditions required to restabilize synaptic AChRs in the denervated muscle were analyzed.

The activity-dependent stabilization of synaptic AChRs in chronically denervated endplates required calcium entry through dihydropyridine-sensitive $\mathrm{Ca}^{2+}$ channels activated by high-frequency stimulation for approximately $6 \mathrm{hr}$ and was specific for synaptic AChRs. As in vivo, extrasynaptic AChRs were not stabilized, and their $t_{1 / 2}$ remained $1 \mathrm{~d}$.

The stabilization process was not dependent on de novo protein synthesis, and it could also be brought about by elevated CAMP levels. Furthermore, it required shorter stimulation periods in the presence of the phosphatase inhibitors okadaic acid and calyculin A, whereas blockade of protein kinases with high doses of staurosporine blocked the stabilization. Activity-dependent, dihydropyridine-sensitive as well as CAMP-dependent phosphorylation of myosin light chain was observed. These findings are consistent with the notion that muscle activity initiates $A C h R$ stabilization via the activation of calcium-dependent protein phosphorylation reactions.

[Key words: acetylcholine receptor, metabolic stability, muscle activity, motor endplate, muscle, development]

The distribution and the behavior of the $\mathrm{ACh}$ receptors (AChRs) in the sarcolemma of skeletal muscle fibers are regulated by innervation. Among the changes in functional receptor properties controlled by the nerve is a drastic reduction in the metabolic degradation rate of the AChR at the synapse: AChRs in the membrane of noninnervated fibers have a metabolic half-

Received May 28, 1992; revised Sept. 21, 1992; accepted Sept. 28, 1992.

This work was supported by grants from the Swiss National Science Foundation and from the Freiwillige Akademische Gesellschaft Basel to H.R.B. The generous gift of (+)PN200-110 and (+)SDZ202-791 from Dr. P. Hof is gratefully acknowledged. We are grateful to Drs. D. Monard and $H$. Suidan for critically reading the manuscript, and to Dr. G. Thomas and Dr. D. Pette (Konstanz) for advice.

Correspondence should be addressed to Dr. H. R. Brenner, Department of Physiology, University of Basel, CH-4051 Basel, Switzerland.

Copyright (C) 1993 Society for Neuroscience 0270-6474/93/131315-11\$05.00/0 life $t_{1 / 2}$ of about $1 \mathrm{~d}$. Within a few days of their accumulation at the site of the neuromuscular contact, the $t_{1 / 2}$ of the synaptic AChRs selectively increases to about 8-15 d (for review, see Reiness and Weinberg, 1981; Salpeter, 1987). The aim of the present study was to analyze the signaling mechanisms by which the motor nerve regulates metabolic stabilization of the synaptic AChRs in rat muscle.

The nerve-induced metabolic stability of synaptic AChRs is a remarkably persistent phenomenon. Although it is at least partially reversed by denervation (Loring and Salpeter, 1980; Stanley and Drachman, 1981), the reversal takes several days to begin. The half-life of the original AChRs present at the time of denervation remains at about $8-12 \mathrm{~d}$ as late as $8 \mathrm{~d}$ after denervation and does not fall below 2-3 d 2-3 weeks later (reviewed in Salpeter and Loring, 1985). An even higher stability following denervation is observed with respect to the synaptic $\mathrm{AChR}$ accumulation and to the persistence of the synaptic folds in the muscle fiber membrane. These observations suggest that the synaptic accumulation of AChRs and their metabolic stability may be related to nerve-induced modifications in the cytoskeleton at the junctional portion of the muscle fiber. Indeed, an accumulation of cytoskeletal proteins (reviewed in Bloch and Pumplin, 1988; Froehner, 1991) as well as synapse-specific coldstable and acetylated microtubules (Jasmin et al., 1990) has been reported at the rat neuromuscular junction.

Recent evidence shows that the electrical activity in the muscle fiber elicited by the motor neuron plays an important role in the control of AChR stability. Thus, exogenous chronic muscle stimulation in vivo following denervation prevents the decrease in $t_{1 / 2}$ of the synaptic AChRs (Brenner and Rudin, 1989) or reverses it if the muscles had been left inactive after denervation (Fumagalli et al., 1990). Conversely, muscle disuse by pharmacological blockade either of action potentials in the motor nerve (Fumagalli et al., 1990) or of neuromuscular transmission (Avila et al., 1989) results in reduction of $t_{1 / 2}$ to values as observed after denervation. Finally, at ectopic synapses that had been denervated during early stages of their development, that is, before stabilization had taken place, muscle stimulation produces, in the absence of the nerve, metabolic stabilization of synaptic AChRs comparable to that during normal development (Rotzler and Brenner, 1990). Therefore, metabolic AChR stability at the synapse is dependent on muscle activity.

The signaling cascades by which electrical activity is linked to AChR stabilization are not known. However, we have found recently that $A C h R$ stabilization can be restored by stimulation in chronically denervated muscle maintained in organ culture and that it is dependent on an influx of $\mathrm{Ca}^{2+}$ ions across voltagegated, dihydropyridine (DHP)-sensitive $\mathrm{Ca}^{2+}$ channels in the sarcolemma (Rotzler et al., 1991). The present study now shows 
that activity-dependent AChR stabilization depends critically on the stimulation pattern used.

In a recent study on denervated mouse endplates, Shyng et al. (1991), have demonstrated that the membrane-permeating cAMP derivative dibutyryl cAMP (DBcAMP) stabilized synaptic AChRs, with the exception of those inserted into the endplate membrane after denervation. In our experiments on rat muscle, AChR stabilization was also brought about by this treatment except that most AChRs appeared stabilized.

Activity-dependent AChR stabilization is independent of de novo protein synthesis. On the other hand, phosphorylation of proteins is involved, as suggested by the synergistic effect that the phosphatase blockers okadaic acid and calyculin $\mathrm{A}$ had on activity-induced AChR stabilization. Furthermore, both $\mathrm{Ca}^{2+}$ and cAMP-dependent AChR stabilizations were consistently preceded by the phosphorylation of proteins comigrating with myosin light chain (MLC) isoforms, demonstrating that $\mathrm{AChR}$ stabilization and a specific phosphorylation pathway in muscle fibers have common activation requirements.

Some of the data on the role of $\mathrm{Ca}^{2+}$ in AChR stabilization have been reported in a previous publication (Rotzler et al., 1991).

\section{Materials and Methods}

The experiments were carried out on endplates of soleus or diaphragm muscles of male Sprague-Dawley rats about $100 \mathrm{gm}$ in weight. All surgical procedures were carried out under Nembutal anesthesia (0.8$1.2 \mathrm{ml} / \mathrm{kg}$ ). For the acute experiments, the animals were killed with $\mathrm{CO}_{2}$. Experimental protocols had been reviewed and approved for animal welfare by the cantonal veterinary authorities of Basel.

Surgical procedures and in vivo stimulation. Soleus muscles were denervated by excision of a $5 \mathrm{~mm}$ piece of the sciatic nerve at the level of the thigh. Left hemidiaphragms were denervated by cutting the phrenic nerve in the thorax.

In one series of experiments, denervated soleus muscles were stimulated electrically in vivo via implanted steel wire electrodes (AS 632, Cooner, Chatsworth, CA), essentially as described by Lamo et al. (1985). The stimuli were $12 \mathrm{~mA}$ pulses of $0.5 \mathrm{msec}$ duration and alternating polarity. They were applied in trains of $1 \mathrm{sec}$ duration at a frequency of $100 \mathrm{~Hz}$, once every $100 \mathrm{sec}$. In another series of experiments, metabolic stability of endplate AChRs was reduced by blocking action potential conduction in the sciatic nerve, rather than by denervation ( $\mathrm{Fu}$ magalli et al., 1990). The blocking procedure was essentially as described previously (Brenner et al., 1987). Briefly, Hanks' solution containing $370 \mu \mathrm{g}$ tetrodotoxin/ml (TTX; Sigma) and $100 \mathrm{U}$ of penicillin $/ \mathrm{ml}$ (Amimed, Basel) was fed, at a rate of $0.5 \mu \mathrm{l} / \mathrm{hr}$, from an osmotic minipump (Alzet 2002) to a Silastic cuff that was fitted around the sciatic nerve in the upper thigh.

Organ culture. The stimulation and maintenance of muscles in organ culture have been described previously (Rotzler et al., 1991). Briefly, muscles were excised 14-20 or 40 d following denervation or conduction block. They were then transferred to a solution containing $40 \%$ Leibowitz's L-15 medium and (in $\mathrm{mM}$ ) $\mathrm{NaCl}, 140 ; \mathrm{KCl}, 4 ; \mathrm{MgCl}_{2}, 2$; and $\mathrm{CaCl}_{2}, 2$; buffered with $5 \mathrm{~mm}$ HEPES to $\mathrm{pH}$ 7.2. The superficial connective tissue of the muscles was dissected away carefully and soleus muscles were reduced to a thin layer of superficial muscle fibers for culturing and to facilitate penetration of drugs. The muscle explants were maintained in organ culture in Trowells T8 medium (GIBCO) supplemented with $0.2 \mathrm{~mm}$ L-glutamine and, per $100 \mathrm{ml}, 100 \mathrm{U}$ of penicillin-streptomycin (Amimed, Basel), $5 \mathrm{mg}$ of gentamicin sulfate (Sigma), $4 \mathrm{mg}$ of conalbumin II (Sigma), $1 \mathrm{mg}$ of ascorbic acid (Sigma), and equilibrated with $10 \% \mathrm{CO}_{2}$ and $90 \% \mathrm{O}_{2}$ at $37^{\circ} \mathrm{C}$. Denervated muscle explants were stimulated with pulses of 2-5 msec duration and 5-15 $\mathrm{mA}$ in amplitude and/or subjected to pharmacological treatments as described below. Blocked muscles were stimulated indirectly via the soleus nerve.

In one series of experiments, the force developed by soleus muscles maintained in culture was measured isometrically by attaching soleus muscles via the Achilles tendon to a force-displacement transducer (Grass FT03C) during the entire stimulation period of $6 \mathrm{hr}$. At the beginning of the experiment, the length of the muscle was adjusted to produce maximal tension, and the resting tension was kept constant by periodic adjustment during the experiment.

Drugs, pharmacological treatments. Cycloheximide (CHX), staurosporine, dibutyryl-cAMP (DBcAMP), dibutyryl-cGMP(DBcGMP), and 3-isobutyl-1-methylxanthine (IBMX) werc purchased from Sigma. Okadaic acid and calyculin A were from LC Services Corp. (Woburn, MA). The dihydropyridines (DHP) (+)PN200-1 10 and (+)SDZ202-791 were a gift from Dr. P. Hof, Sandoz Ltd. (Basel). Most drugs were added to the culture medium from 1000 -fold concentrated stock solutions for the times indicated in Table 1. For preparation of stock solutions, drugs were dissolved either in dimethyl sulfoxide (staurosporine, okadaic acid, calyculin A, IBMX) or in 96\% ethanol [(+)PN200-110, (+)SDZ2027911 . DBcAMP and DBcGMP were dissolved directly in Trowells T8 culture medium. After pharmacological or stimulation treatments, all muscles were washed and maintained for the entire culturing period in the presence of TTX (Sigma; $10^{-8} \mathrm{M}$ ) to suppress fibrillation.

Autoradiography. The methods for autoradiography were essentially as described (Rotzler and Brenner, 1990; Rotzler et al., 1991). For each experiment, two to eight pairs of contralateral soleus muscles were treated identically. They were then incubated together with pairs of untreated control muscles in a solution containing $0.5-1 \mu \mathrm{g} / \mathrm{ml}{ }^{125} \mathrm{I}-\alpha$-bungarotoxin ( $\alpha$-BuTX; Amersham; specific activity, $>200 \mathrm{Ci} / \mathrm{mmol}$ ) for $2-4$ $\mathrm{hr}$. After rinsing, one muscle of each identically treated pair was incubated overnight at $4{ }^{\circ} \mathrm{C}$ in oxygenated Krebs' solution and fixed in $2.5 \%$ glutaraldehyde in PBS, while the other was transferred again into organ culture for up to $96 \mathrm{hr}$. At the end of cultivation, the viability of the muscles was ascertained by visual examination of twitch contractions in response to electrical stimulation, and the muscles were fixed in $2.5 \%$ glutaraldehyde. Muscle segments containing the endplates were dispersed ultrasonically and muscle fibers were transferred in water suspension onto gelatin-coated slides. After drying, the slides were thoroughly rinsed in tap water and coated with Ilford L4 emulsion diluted $1: 4$ in $2 \%$ glycerol. Exposure was at room temperature for 3-24 hr. Autoradiograms were developed in Kodak D19 developer, fixed in Kodak Rapid Fix, dried, and embedded in Eukitt (ABS, Basel, Switzerland). Autoradiograms were viewed on a Zeiss Standard microscope with darkfield illumination at $160-1000 \times$. Autoradiograms were developed before the highest grain density had reached $0.4-0.8 / \mu \mathrm{m}^{2}$. Even beyond this range of grain densities, the response of the emulsion was linear.

Determination of AChR half-lives. To determine metabolic AChR stabilities, densities of autoradiographic silver grains at junctional and extrajunctional membranes were counted at $1000 \times$ magnification in dark-field illumination, using the ocular grid of the microscope, and background densities were subtracted (Reiness and Weinberg, 1981). For each membrane area examined in a fiber, three independent counts were made and averaged. The mean of the endplate grain densities of the muscles fixed immediately after labeling with ${ }^{125}$ I- $\alpha$-BuTX was set to $100 \%$, and the endplate grain densities determined in the cultured contralateral muscles were normalized to this value. This allowed pooling of data from different sets of experiments carried out with identical protocols but different exposure times or different activities of ${ }^{125} \mathrm{I}-\alpha$ BuTX.

The metabolic stability of the labeled AChRs was then determined from the rate of loss of specific endplate grain density as a function of time in culture. All normalized data points $(n)$ from an experiment were fitted by the Levenberg-Marquart method, assuming first-order kinetics for AChR degradation. Since in a few experiments, AChR degradation appeared to deviate from a single exponential and the presence of two populations of AChRs with different half-lives could not always be excluded, the calculated values of AChR half-lives are only approximations, and were thus termed $t_{i, \text { app }}$. Metabolic stabilities of the AChRs were expressed in terms of their half-lives $t_{1 / 2}$, which in turn were calculated from $t_{1 / 2, a p p}=\ln 2 / k_{\text {app }}$, where $k_{\text {app }}$ is the apparent rate constant of the AChR degradation. Values of $k_{\text {app }} \pm$ SD from control and test muscles were tested for differences, using the two-tailed Student's $t$ test. The estimated half-lives $t_{1 / 2 \text { app }}$ were corrected for unbinding of ${ }^{125} I-\alpha$ BuTX from the AChRs according to $1 / t_{1 / 2}$ (degradation) $=1 / t_{1 / 2}$ (measured) - $1 / t_{1 / 2}$ (unbinding) (Salpeter et al., 1986), with $t_{1 / 2}$ (unbinding) $=36 \mathrm{~d}$ (Bevan and Steinbach, 1983).

Biochemical methods. To determine the extent of protein synthesis inhibition in the presence of cycloheximide, explants were preincubated for $1 \mathrm{hr}$ in culture medium with or without $50 \mu \mathrm{g} / \mathrm{ml}$ cycloheximide. 
Table 1. Effects of stimulation and/or pharmacological treatments on the apparent half-life $\left(t_{1 / 2, a p p}\right)$ of synaptic AChRs

\begin{tabular}{|c|c|c|c|}
\hline Protocol & $\begin{array}{l}k_{\text {app }}( \pm \mathrm{SD}) \\
\left(\times 10^{-3} \mathrm{hr}^{-1}\right) \\
\end{array}$ & $\begin{array}{l}t_{1 /, \mathrm{app}} \\
\text { (d) }\end{array}$ & $\begin{array}{l}\text { \# of } \\
\text { endplates } \\
\text { examined/ } \\
\text { \# of } \\
\text { muscle } \\
\text { pairs } \\
\end{array}$ \\
\hline \multicolumn{4}{|l|}{ A. Denervated controls } \\
\hline Denervated for $17 \pm 3 \mathrm{~d}$ (pooled data) & $10.74 \pm 0.87$ & 2.9 & $145 / 10$ \\
\hline Denervated for $40 \mathrm{~d}$ & $9.11 \pm 1.15(\mathrm{NS})$ & 3.5 & $20 / 1$ \\
\hline \multicolumn{4}{|l|}{ B. Stimulation patterns } \\
\hline $4.5 \mathrm{hr}, 100$ pulses per train, $100 \mathrm{~Hz}$ & $7.17 \pm 1.06(\mathrm{NS})$ & 4.5 & $72 / 4$ \\
\hline $6 \mathrm{hr}, 100$ pulses per train, $100 \mathrm{~Hz}$ & $2.41 \pm 0.78$ & 18.0 & $67 / 4$ \\
\hline $6 \mathrm{hr}, 100$ pulses per train, $100 \mathrm{~Hz}$, in vivo & $3.17 \pm 0.50$ & 12.2 & $82 / 5$ \\
\hline $6 \mathrm{hr}, 100$ pulses per train, $20 \mathrm{~Hz}$ & $7.58 \pm 0.85(\mathrm{NS})$ & 4.3 & $103 / 4$ \\
\hline $12 \mathrm{hr}, 100$ pulses per train, $20 \mathrm{~Hz}$ & $10.88 \pm 0.73(\mathrm{NS})$ & 2.9 & $48 / 2$ \\
\hline $6 \mathrm{hr}, 60$ pulses per train, $100 \mathrm{~Hz}$ & $7.32 \pm 1.04(\mathrm{NS})$ & 4.4 & $58 / 3$ \\
\hline $6 \mathrm{hr}, 100$ pulses per train, $100 \mathrm{~Hz}$, muscles labeled with ${ }^{125} \mathrm{I}-\alpha$-BuTX before stimulation & $3.47 \pm 0.66$ & 10.8 & $66 / 3$ \\
\hline \multicolumn{4}{|l|}{ C. Stimulation, long-time denervation } \\
\hline Denervated for $40 \mathrm{~d}$, stimulated for $6 \mathrm{hr}$ in vitro & $2.80 \pm 1.13$ & 14.5 & $20 / 1$ \\
\hline \multicolumn{4}{|l|}{ D. Cyclic nucleotides } \\
\hline $24 \mathrm{hr}$ DBcAMP (0.5 mм) & $3.35 \pm 0.70$ & 11.3 & $80 / 4$ \\
\hline $24 \mathrm{hr}$ DBcGMP (0.5 mM) & $8.34 \pm 0.79(\mathrm{NS})$ & 3.8 & $76 / 4$ \\
\hline \multicolumn{4}{|l|}{ E. Drugs affecting $\mathrm{Ca}^{2+}$ entry through DHP-sensitive $\mathrm{Ca}^{2+}$ channels } \\
\hline $12 \mathrm{hr}$ in vitro stimulation & $3.85 \pm 0.85$ & $11.1^{\circ}$ & $58 / 4$ \\
\hline $12 \mathrm{hr}$ in vitro stimulation with D600 $(10 \mu \mathrm{M})$ & $13.54 \pm 1.26(\mathrm{NS})$ & $2.3^{a}$ & $56 / 3$ \\
\hline $24 \mathrm{hr}$ in vitro stimulation & $3.00 \pm 1.03$ & $13.1^{a}$ & $59 / 4$ \\
\hline $24 \mathrm{hr}$ in vitro stimulation with (+)PN200-1 $10(1 \mu \mathrm{M})$ & $13.58 \pm 1.56(\mathrm{NS})$ & $2.3^{a}$ & $70 / 5$ \\
\hline $24 \mathrm{hr} \mathrm{KCl} \mathrm{(15} \mathrm{mм)}$ & $9.95 \pm 0.65(\mathrm{NS})$ & 3.2 & $104 / 5$ \\
\hline $24 \mathrm{hr} \mathrm{KCl}(15 \mathrm{~mm})$ with (+)SDZ202-791 (5 $\mu \mathrm{M})$ & $3.97 \pm 0.66$ & 9.1 & $95 / 6$ \\
\hline \multicolumn{4}{|l|}{ F. $\mathrm{Ca}^{2+}$ entry through AChR channels } \\
\hline Nerve blocked with TTX for $14 \mathrm{~d}$ & $10.16 \pm 1.47(\mathrm{NS})$ & 3.1 & $17 / 1$ \\
\hline $14 \mathrm{~d}$ TTX blocked and nerve stimulated for $6 \mathrm{hr}$ in vitro & $2.91 \pm 0.59$ & 13.7 & $37 / 2$ \\
\hline $14 \mathrm{~d}$ TTX blocked and nerve stimulated for $6 \mathrm{hr}$ with (+)PN200-110 & $10.72 \pm 0.96(\mathrm{NS})$ & 2.9 & $62 / 3$ \\
\hline \multicolumn{4}{|l|}{ G. Blockade of protein synthesis } \\
\hline $6 \mathrm{hr}$ in vitro stimulated with cycloheximide $(50 \mu \mathrm{g} / \mathrm{ml})$ & $2.58 \pm 0.58$ & 16.3 & $59 / 3$ \\
\hline \multicolumn{4}{|l|}{ H. Drugs affecting protein phosphorylation } \\
\hline $3 \mathrm{hr}$ in vitro stimulation $+3 \mathrm{hr}$ inactive & $9.34 \pm 0.72$ (NS) & 3.4 & $48 / 2$ \\
\hline $3 \mathrm{hr}$ in vitro stimulation $+3 \mathrm{hr}$ inactive, all in okadaic acid (200 $\mathrm{nM})$ & $5.27 \pm 0.88$ & 6.5 & $52 / 2$ \\
\hline $4.5 \mathrm{hr}$ in vitro stimulation $+1.5 \mathrm{hr}$ inactive, all in okadaic acid ( $200 \mathrm{~nm})$ & $3.17 \pm 0.71$ & 12.2 & $106 / 4$ \\
\hline $4.5 \mathrm{hr}$ in vitro stimulation $+1.5 \mathrm{hr}$ inactive, all in calyculin $\mathrm{A}(10 \mathrm{nM})$ & $3.89 \pm 0.61$ & 9.3 & $82 / 4$ \\
\hline $6 \mathrm{hr}$ in vitro stimulation with staurosporine $(2 \mu \mathrm{M})$ & $11.61 \pm 0.96(\mathrm{NS})$ & 2.7 & $84 / 4$ \\
\hline
\end{tabular}

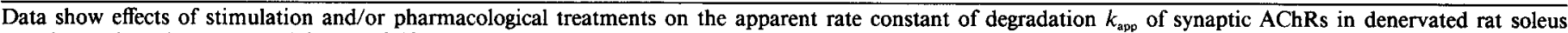

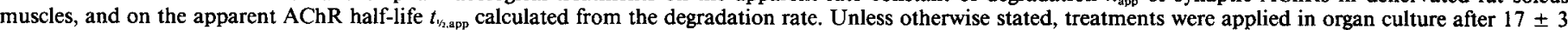

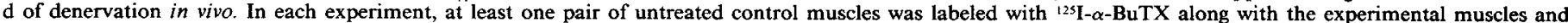

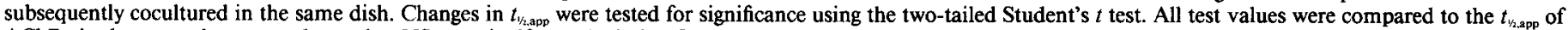
AChRs in denervated, untreated muscles. NS, nonsignificant deviation from untreated control.

${ }^{a}$ Reproduced from Rotzler et al. (1991).

After the addition of ${ }^{35} \mathrm{~S}$-labeled amino acids $(0.1 \mathrm{mCi} / \mathrm{ml}, 1000 \mathrm{Ci} /$ mmol; Translabel, Amersham), explants were stimulated for $6 \mathrm{hr}$. Samples were then rinsed in Trowells T8 and frozen in liquid nitrogen, pulverized, boiled in SDS-PAGE sample buffer for $10 \mathrm{~min}(50 \mathrm{mg}$ wet weight of tissue per $\mathrm{ml}$ of sample buffer), and solubilized proteins were fractionated on 13\% gels (Laemmli, 1970). Proteins were then stained with Coomassie blue and gels were dried and exposed to $\mathrm{x}$-ray film (AR5, Kodak). ${ }^{35} \mathrm{~S}$ incorporation into corresponding bands of comparable Coomassie blue labeling intensity was determined by densitometry.

To analyze protein phosphorylation patterns during AChR stabilization protocols, explants were preincubated for $1 \mathrm{hr}$ in culture medium with $0.1 \mathrm{mCi} / \mathrm{ml}$ of ${ }^{32} \mathrm{P}$-orthophosphate. Explants were then treated in the continued presence of ${ }^{32} \mathrm{P}_{\mathrm{i}}$ as described above. Immediately following the last stimulus train, ice-cold PBS was added for rinsing for about
$30 \mathrm{sec}$. Explants were then fixed immediately in ice-cold $7 \%$ trichloroacetic acid, dissected, and frozen in liquid nitrogen. Special care was taken to keep the time between interruption of electrical stimulation and freezing to less than $60 \mathrm{sec}$. Frozen tissues were pulverized in liquid nitrogen, and incubated under vigorous agitation in isoelectric focusing (IEF) sample buffer [pH 3-10 and pH 2.5-5 ampholites (Sigma) in a ratio of $2: 1,100 \mathrm{mg}$ of tissue wet weight per $\mathrm{ml}$ of IEF sample buffer] (O'Farrell, 1975). Solubilized proteins were then focused for $16 \mathrm{hr}$, followed by $12 \%$ SDS-PAGE. Finally, proteins were stained with Coomassie blue, and gels were dried and exposed to x-ray film (AR5, Kodak) to detect ${ }^{32} \mathrm{P}$-labeled species. Labeling patterns from independent complete experimental sets were very similar, and data from representative experiments are shown. Approximately equal amounts of Coomassielabeled protein were detected on each gel, and all data are from $3 \mathrm{~d}$ exposures to $\mathrm{x}$-ray film. 

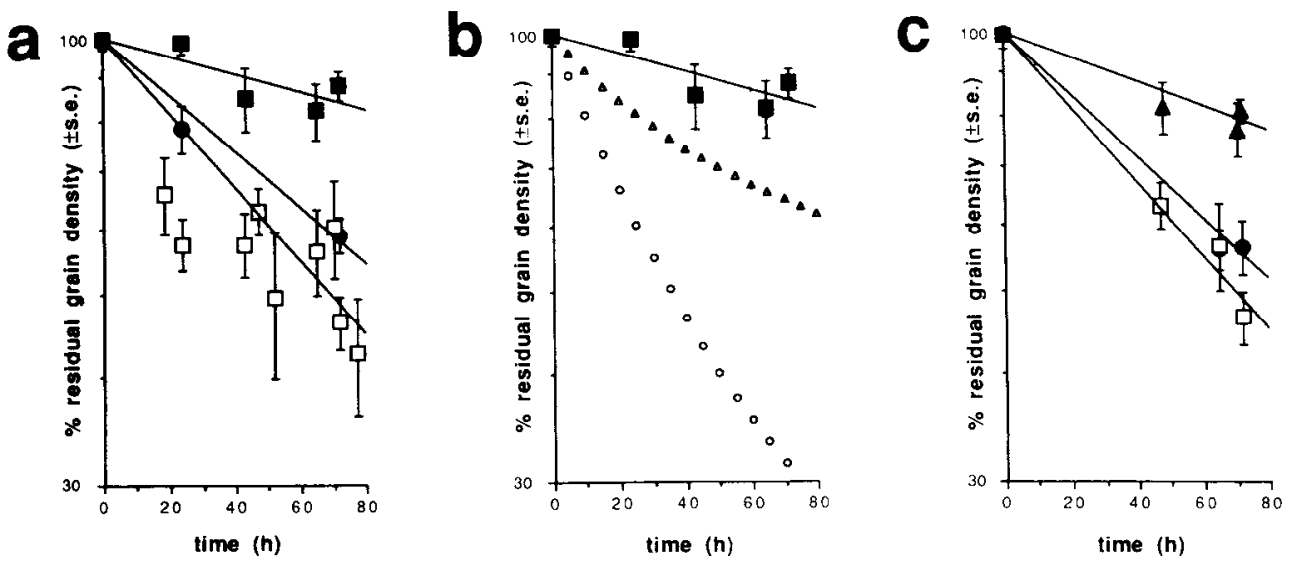

Figure 1. Stabilization of synaptic AChRs in chronically denervated rat soleus muscle explants in vitro. a, Dependence of degradation of endplate AChR- $\alpha$-BuTX complexes on the pattern of muscle stimulation. At $17 \mathrm{~d}$ postdenervation, muscle explants were stimulated for $6 \mathrm{hr}$ with short, high-frequency $(\square, 100 \mathrm{~Hz}$ trains, $1 \mathrm{sec}$ duration, once per $100 \mathrm{sec})$ or long, low-frequency $(\bullet ; 20 \mathrm{~Hz}, 5 \mathrm{sec}$, once per $100 \mathrm{sec})$ trains of stimuli. Note that in spite of the similar number of stimuli applied in both protocols, only high-frequency stimulation stabilizes synaptic AChRs. $\square$, synaptic AChR degradation in unstimulated muscle. Apparent half-lives $t_{1 / 2, a p p}$ were $18.0(\square), 4.3(\Theta)$, and $2.8 \mathrm{~d}(\square)$, respectively. $b$, Degradation of AChR$\alpha$-Bu'TX complexes after high-frequency stimulation (same data as in $a$ ), compared to the expected time courses of degradation assuming that $75 \%$ $(O)$ or $30 \%(\Lambda)$ of the synaptic AChRs were resistant to stabilization by stimulation and $t_{v_{2, a p p}}$ of 1 and $10 \mathrm{~d}$, respectively. Note that only the curve assuming stabilization of all AChRs (solid line) represents a good fit of the data. $c$. Effects of membrane-permeant analogs of cyclic nucleotides on degradation of AChR $-\alpha$-BuTX complexes in unstimulated muscle. $\Delta$, after $24 \mathrm{hr}$ of treatment with $0.5 \mathrm{mM} \mathrm{DBcAMP}, t_{1 /, \text { app }}=9.8 \mathrm{~d}$;, , after $24 \mathrm{hr}$ treatment with $0.5 \mathrm{mM}$ DBcGMP, $t_{1 /, \text { app }}=3.8 \mathrm{~d}$; $\square$, untreated controls, $t_{i_{2, \text { app }}}=2.8 \mathrm{~d}$.

Anti-myosin light chain monoclonal antibody (MY-21) was from Sigma. To test its reaction with rat muscle myosins, myofibrils were extracted from rat soleus muscles and run on two-dimensional gels. Immunoblotting then showed that $M Y-21$ recognized major protein species as detected in Coomassie stains of both myofibrils and diaphragm homogenates (see arrowheads in Fig. 5c), indicating that MY. 21 does indeed recognize skeletal myosins. As cxpected for diaphragm muscle both fast and slow light chain species were detected. Bound antibodies were visualized with alkaline phosphatase-coupled second antibodies (Boehringer-Mannheim).

For analysis of cAMP contents of muscle explants after stimulation, explants were fixed and frozen within $30 \mathrm{sec}$ of the last stimulation. In some experiments, to minimize possible cAMP degradation, 1 mM IBMX was added to the culture medium during stimulation, and explants were not dissected following stimulation, allowing freezing within less than 15 sec. cAMP contents were determined by a competition assay with specific binding protein according to the recommendations of the manufacturer ( ${ }^{3} \mathrm{H}$-cAMP kit, Amersham): frozen muscles were pulverized and then extracted in aqueous ethanol as recommended by the manufacturer. Exogenous cAMP added in increasing amounts to the muscle homogenates produced responses that were comparable to those obtained from standard determinations in water, indicating that endogenous cAMP was not significantly degraded.

\section{Results}

Metabolic stabilization of synaptic AChRs can be induced by muscle stimulation in organ culture

Even in the absence of the nerve, the low metabolic half-life of the AChRs in the endplate membrane of chronically denervated rat muscle can be increased to that observed in innervated controls when the muscles are stimulated in trains of $100 \mathrm{~Hz}$ and $1 \mathrm{sec}$ duration applied once every $100 \mathrm{sec}$ (Fumagalli et al., 1990; Rotzler et al., 1991). Using this stimulation pattern, we first established the minimum amount of stimulation required for synaptic AChR stabilization in muscles that had been denervated for $17 \pm 3 \mathrm{~d}$. At this postdenervation time, $t_{1 / 2, \text { app }}$ of synaptic AChRs in unstimulated muscle averaged $2.9 \mathrm{~d}$. Restabilization was observed when the chronically denervated muscles were stimulated for as little as $6 \mathrm{hr}$ (Fig. $1 a$ ) and was independent of whether the muscles were stimulated in vivo or whether they were excised from the animal and were subsequently stimulated in organ culture: the $t_{y_{1 / 2} \text { app }}$ of synaptic AChRs in muscles stimulated in vivo averaged $12.2 \mathrm{~d}$; that after stimulation in organ culture was $18.0 \mathrm{~d}$. In contrast, the synaptic AChRs in unstimulated muscles remained unstable, their halflives averaging $2.8 \mathrm{~d}$. The effect of stimulation was specific on synaptic AChRs with the stability of extrasynaptic AChRs remaining unaffected $\left(t_{1 /, a p p}=1.0 \mathrm{~d}\right)$. Similar results were obtained when AChRs were labeled with ${ }^{125} \mathrm{I}-\alpha$-BuTX before the stimulation $\left(t_{1 / 2 \text { apd }}=10.8 \mathrm{~d}\right)$, and when stimulation was begun as late as $40 \mathrm{~d}$ after denervation $\left(t_{1 /, \mathrm{app}}=14.5 \mathrm{~d}\right)$. The data described so far are summarized in more detail in Table $1 A, B$.

The similarity of the results derived from muscles stimulated in vivo and in vitro strongly suggests that the effect of stimulation on AChR stability observed in organ cultured muscle was not a culture artifact. All stimulations and pharmacological treatments described below were therefore applied to organ cultured muscle. As will be seen below, the effects were again specific on endplate AChRs, while the half-lives $t_{1 / 2, \text { app }}$ of extrajunctional AChRs were not measurably affected.

As mentioned above, $6 \mathrm{hr}$ was the lower limit of high-frequency stimulation required to produce $A C h R$ stabilization while stimulation for $3 \mathrm{hr}$ or $4.5 \mathrm{hr}$, although producing slightly higher estimates of $t_{1 / 2, a p p}$, was not sufficient to produce AChR stabilities that were significantly different from those observed in unstimulated muscle. To exclude the possibility that the inefficiency of short-term $(<6 \mathrm{hr}$ ) stimulation was not due to the low amount of stimulation applied but rather to the limited time allowed for AChR stabilization, muscles were stimulated for $3 \mathrm{hr}$ and then left unstimulated for 3 more $\mathrm{hr}$ before they were labeled. The $t_{1 / 2, \text { app }}$ of synaptic AChRs was then $3.4 \mathrm{~d}$ (Table $1 H$ ), showing that AChR stabilization indeed requires $6 \mathrm{hr}$ of high-frequency stimulation ( $100 \mathrm{~Hz}$ trains, $1 \mathrm{sec}$ duration, once every $100 \mathrm{sec}$ ).

Receptor stabilization was critically dependent on the stimulation pattern used. When muscles were stimulated in trains of lower frequency (i.e., $20 \mathrm{~Hz}$ ) but of longer duration (i.e., 5 
sec), such that the total number of stimuli applied was equal to that applied during the high-frequency trains of shorter duration, the synaptic AChRs were not stabilized, neither after 6 nor after $12 \mathrm{hr}$ of stimulation. As shown in Figure $1 a$ and Table $1 B$, $t_{1 / 2, \text { app }}$ of the synaptic AChRs then remained at 4.3 and $2.9 \mathrm{~d}$, respectively. Similarly, when muscles were stimulated for $6 \mathrm{hr}$ with high-frequency trains containing 60 pulses only $(100 \mathrm{~Hz}$, once per $100 \mathrm{sec}$ ) rather than 100 pulses per train, no stabilization of synaptic AChRs was observed, $t_{1 / 2, \text { app }}$ remaining at 4.4 d (Table $1 B$ ).

The metabolic stabilization of synaptic AChRs induced by high-frequency stimulation is maintained for at least $4 \mathrm{~d}$, that is, the time for which the cultures were maintained after stimulation. This raised the question whether AChR stability induced by stimulation is as persistent following interruption of stimulation as is the AChR stability in normal muscle following acute denervation. We have examined this question by comparing the time for which stimulation-induced AChR restabilization is maintained with the time for which AChRs remain stable after acute denervation. For this purpose, soleus muscles were denervated, and $17 \mathrm{~d}$ later they were restabilized by stimulation in vivo for $6 \mathrm{hr}$. At the end of the stimulation period, control muscles in another animal were denervated. After another $6 \mathrm{~d}$, the muscles from both animals were excised, labeled with ${ }^{125} \mathrm{I}-\alpha-\mathrm{BuTX}$, and cocultured in the same dish for $3 \mathrm{~d}$. Since at $6 \mathrm{~d}$ postdenervation, the stabilities of endplate AChRs in rat muscle are not uniform (Brett et al, 1982), we compared in this experiment the percentage of labeled AChRs remaining after culturing in the two types of muscles. They were $72 \pm 4 \%( \pm \mathrm{SE}$, $n=24$ ) at synapses where AChRs had been stabilized by stimulation and $70 \pm 4 \%( \pm \mathrm{SE}, n=24)$ at synapses whose $\mathrm{AChRs}$ had been kept stable by innervation until $6 \mathrm{~d}$ prior to labeling, indicating similar temporal persistence of AChRs stabilized by stimulation and by innervation.

\section{Synaptic AChRs are metabolically stabilized in the absence of stimulation by treatments with ionophore A23187 or with $D B C A M P$}

The finding that metabolic AChR stability could be induced by muscle stimulation in organ culture allowed us to investigate the pathway mediating the activity dependence by pharmacological means. Two compounds known to act as intracellular messengers have been shown to be regulated by muscle activity: $\mathrm{Ca}^{2+}$ and cGMP (Nestler et al., 1978).

Our previous finding (Rotzler et al., 1991) that treatment of chronically denervated muscles with the $\mathrm{Ca}^{2+}$ ionophore A23187 produced stabilization selectively of synaptic AChRs in the absence of stimulation is consistent with a role for $\mathrm{Ca}^{2+}$ in mediating the activity dependence of this process. As with stimulation, no effect of ionophore treatment on the apparent halflife of the extrasynaptic AChRs could be observed.

Following short bursts of muscle activity, cGMP has been shown to increase twofold in frog muscle (Nestler et al., 1978). To test for a possible involvement of cGMP in AChR stabilization, chronically denervated muscles containing synaptic AChRs with low metabolic stability were cultured in the absence of stimulation in medium containing the membrane-permeant cGMP analog DBcGMP at a concentration of $0.5 \mathrm{~mm}$. After 24 $\mathrm{hr}$ of treatment, the $t_{\psi_{2} \text { app }}$ of the synaptic AChRs was at $3.8 \mathrm{~d}$, that is, similar to that in untreated controls $(2.8 \mathrm{~d})$ (Fig. $1 c$, Table $1 D$ ). Thus, an increase in intracellular levels of cGMP by muscle activity does not appear to be responsible for activity- dependent AChR stabilization. In contrast, when the same experiment was carried out in the presence of the membranepermeant cAMP analog DBcAMP at $0.5 \mathrm{mM}$, the $t_{1 / 2, \text { app }}$ of synaptic AChRs was selectively increased to $11.3 \mathrm{~d}$; again, the $t_{1 / 2, \text { app }}$ of the extrasynaptic AChRs was unaffected (Fig. 1c, Table $1 D$ ). Unlike with high-frequency muscle stimulation, however, $6 \mathrm{hr}$ of treatment with DBcAMP was not sufficient to stabilize the AChRs, the $t_{1 / 2, \text { app }}$ remaining at $5.0 \mathrm{~d}$. In a recent independent study on mouse sternomastoid muscle, a similar effect of cAMP on AChR stability has been reported (Shyng et al., 1991).

To determine whether endogenous cAMP is itself regulated by muscle activity in the time scale found to control receptor stability, we measured the levels of cAMP in muscles that were stimulated for $6 \mathrm{hr}$ with the fast stimulation pattern as defined above. For better resolution of possible synapse specific changes, cAMP levels in synapse-free and synapse-enriched segments were analyzed separately. Optimal division in such segments is achieved in the diaphragm with its narrow endplate band rather than the soleus muscle where endplates are widely distributed over its central portion comprising about two-thirds of its mass. Therefore, effects of stimulation on AChR stability and on cAMP levels were analyzed in rat diaphragms that had been denervated $14 \mathrm{~d}$ earlier. As in the soleus, $6 \mathrm{hr}$ of stimulation were sufficient for stabilizing the synaptic AChRs in the diaphragm, their halflife $t_{1 /, \text { app }}$ being $10.6 \mathrm{~d}$. However, as in frog muscle (Nestler et al., 1978), cAMP levels in rat diaphragm were independent of stimulation. The cAMP contents of endplate-enriched stimulated and nonstimulated muscle segments averaged 1.14 and $1.02 \mathrm{pmol} / \mathrm{mg}$ protein, respectively, and those in endplate-free segments were 0.98 and $1.06 \mathrm{pmol} / \mathrm{mg}$ protein $(n=4$ in each group). The coefficient of variation was $<0.15$ for all groups. Similar results were obtained when stimulation was performed in the presence of the phosphodiesterase-inhibitor IBMX (1 $\mathrm{mM}$ ). Thus, we could not resolve a role of cAMP in mediating the activity dependence of synaptic AChR stabilization.

AChR stabilization by stimulation is prevented by $\mathrm{Ca}^{2+}$
channel blockers and is induced by $\mathrm{Ca}^{2+}$ channel
activator in inactive muscles

The experiments described above are consistent with the notion that AChR stabilization arises from an increase in the intracellular $\mathrm{Ca}^{2+}$ activity. Two ways are known by which $\mathrm{Ca}^{2+}$ ions may enter the myoplasm during stimulation-induced muscle activity: (1) by an influx through voltage-dependent $\mathrm{Ca}^{2+}$ channels in the sarcolemma, and (2) by the release from the sarcoplasmic reticulum (SR), thus initiating muscle contraction. A third possibility in innervated muscle is that $\mathrm{Ca}^{2+}$ enters the fiber through endplate AChR channels when the muscle is activated by the nerve through the release of ACh (Miledi et al., 1980; Decker and Dani, 1990).

Previous experiments have indicated (Rotzler et al., 1991) that, indeed, $\mathrm{Ca}^{2+}$ influx through slowly gating, voltage-activated $\mathrm{Ca}^{2+}$ channels in the muscle fiber membrane is involved in receptor stabilization, as the addition of the $\mathrm{Ca}^{2+}$ channel blocker D600 $(10 \mu \mathrm{M})$ or $(+)$ PN200-1 $10(1 \mu \mathrm{M})$ to the culturing medium during stimulation blocked the activity-induced stabilization of the synaptic AChRs. Conversely, addition of the $\mathrm{Ca}^{2+}$ channel activator $(+) \mathrm{SDZ202-791}(5 \mu \mathrm{M})$ to the culturing medium containing elevated $\mathrm{K}^{+}(15 \mathrm{~mm})$ caused, in the absence of stimulation, selective stabilization of synaptic AChRs. The results from these previous experiments are summarized for completeness in Figure $2 a$ and Table $1 E$. 

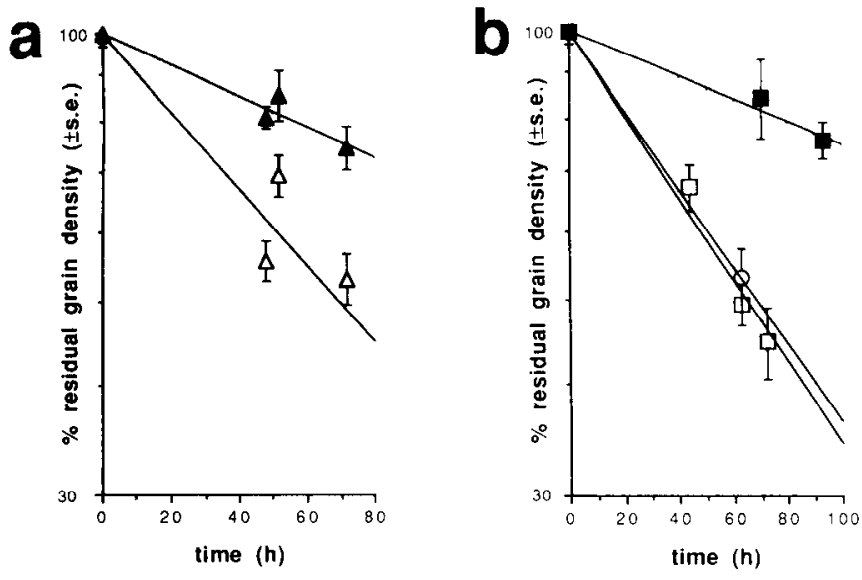

Figure 2. Activity-dependent stabilization of synaptic AChRs is mediated by $\mathrm{Ca}^{2+}$ entry through DHP-sensitive $\mathrm{Ca}^{2+}$ channels. $a$, Stabilization of AChRs is induced in the presence of $\mathrm{Ca}^{2+}$ channel activator $(+)$ SDZ202-791 in unstimulated muscle. Experimental muscles were maintained in $15 \mathrm{~mm} \mathrm{~K}^{+}$while they were exposed to the activator $(\Delta)$, and in parallel experiments, control muscles $(\triangle)$ were exposed to 15 $\mathrm{mM} \mathrm{K}^{+}$alone for the same time $(24 \mathrm{hr}): t_{\mathrm{y}_{\mathrm{z}, \mathrm{app}}}=9.1 \mathrm{~d}$ and $3.1 \mathrm{~d}$, respectively. $b$, Activity-induccd AChR stabilization is prevented by the $\mathrm{Ca}^{2+}$ channel blocker (+)PN200-110 in muscles activated via stimulation of the soleus nerve for $6 \mathrm{hr}\left(t_{t_{2, \text { app }}}\right.$ reduced from 18.3 to $\left.3.1 \mathrm{~d}\right)$. Degradation of AChRs in nerve-stimulated muscle with $(\square)$ and without $(\square)(+)$ PN200-110, and in unstimulated muscle $(O)$. AChR stability had been reduced by chronic ( $14 \mathrm{~d}$ ) blockade of action potential conduction in the sciatic nerve with TTX, and effectiveness of neuromuscular transmission during the stimulation period was ascertained visually from tetanic muscle contractions.

In contrast, $\mathrm{Ca}^{2+}$ released from the $\mathrm{SR}$ is but marginally involved, if at all. Quantitative measurements of muscle contraction during an entire stimulation period of $6 \mathrm{hr}$ showed that (+)PN200-110 did not abolish isomctric muscle contractions. Thus, stabilization was blocked by DHP in spite of the release of $\mathrm{Ca}^{2}+$ from the SR. Combined with our previous finding (Rotzler et al., 1991) that $t_{1 /, \text { app }}$ is not affected by $\mathrm{Ca}^{2+}$ released from the SR by ryanodine (Fairhurst and Hasselbach, 1970), these results do not support a role for $\mathrm{Ca}^{2+}$ release from the SR in the stabilization process.

To test the possibility that, in innervated muscle, $\mathrm{Ca}^{2+}$ influx through endplate channels controls AChR stability, the AChRs of the soleus muscle were destabilized in vivo by blocking chronically the action potential conduction in the sciatic nerve with TTX (Fumagalli et al., 1990). The muscle with a piece of nerve attached was then excised and stimulated indirectly, that is, via the nerve, in the presence and the absence of (+)PN200-110 with the high-frequency stimulation pattern for $6 \mathrm{hr}$. In the presence of the blocker, the half-life of the synaptic AChRs remained at $t_{t_{1, \text { app }}}=2.9 \mathrm{~d}$; in the absence of the blocker, $t_{1 /, \text { anp }}$ was, like upon direct stimulation, increased to $13.7 \mathrm{~d}$ (Table $1 F$ ). The $t_{1 / \text { app }}$ of AChRs in muscles that were not stimulated following the TTX blockade averaged $3.1 \mathrm{~d}$ (Fig. $2 b$, Table $1 F$ ). Therefore, $\mathrm{Ca}^{2+}$ entering through endplate AChR channels appears not to be involved in the metabolic stabilization of endplate AChRs.

\section{Phosphorylation but not protein synthesis is involved in the activity-dependent AChR stabilization}

The activity-dependent $\mathrm{Ca}^{2+}$ influx might induce AChR stabilization via the posttranslational modification of preexisting factors such as the phosphorylation of proteins. For example, a number of cytoskeletal proteins are modulated by phosphorylation (reviewed in Boivin, 1988), some of which are thought to be involved in the positional and metabolic stabilization of the AChRs (reviewed in Bloch and Pumplin, 1988). Alternatively, stabilization could depend on the de novo synthesis of protein factors.

To test for a possible involvement of protein phosphorylation in the stabilization process, we blocked intracellular phosphatases by treating the muscles with okadaic acid (Bialojan and Takai, 1988) or with calyculin A (Ishihara et al., 1989). In a first series of experiments, we stimulated muscles in the presence of $200 \mathrm{nM}$ okadaic acid for $3 \mathrm{hr}$ with the high-frequency stim-
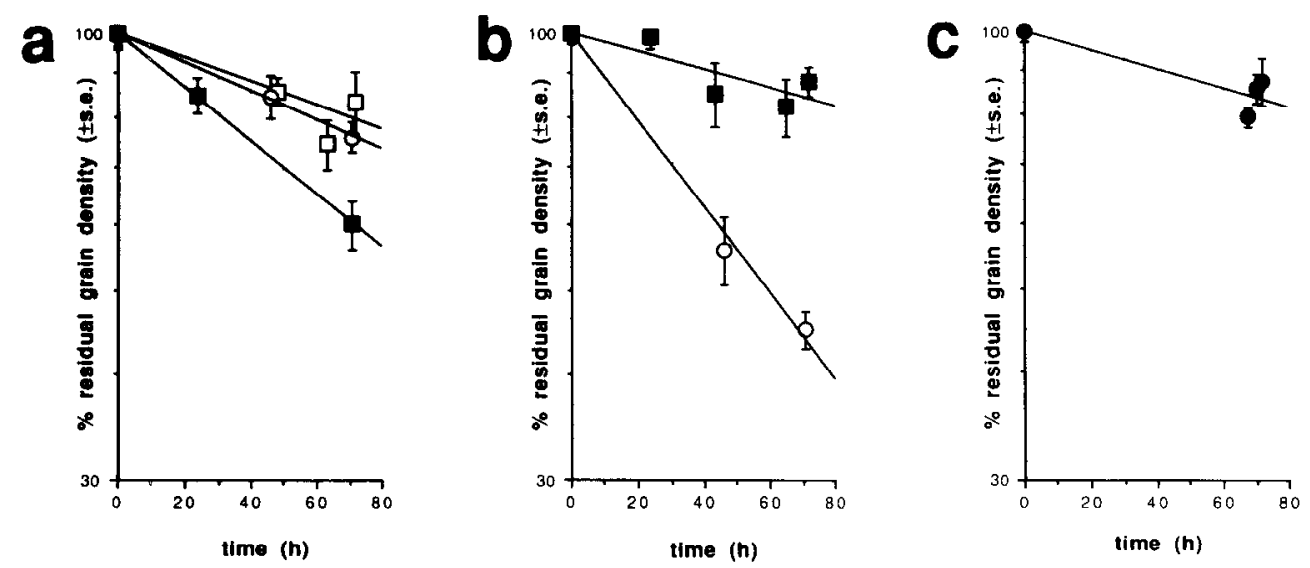

Figure 3. Activity-induced AChR stabilization depends on the phosphorylation of proteins but not on de novo protein synthesis. $a$, The phosphatase inhibitors okadaic acid ( $200 \mathrm{nM})$ and calyculin A (10 nM) reduce the amount of stimulation required to produce AChR stabilization. Data show degradation of synaptic AChRs after $4.5 \mathrm{hr}$ of stimulation, followed by $1.5 \mathrm{hr}$ without stimulation, all in the presence of okadaic acid ( $\square$; $t_{1 / 2, \text { app }}=$ $12.2 \mathrm{~d})$ or of calyculin $\mathrm{A}\left(\mathrm{O} ; t_{1 / 2, \mathrm{apD}}=9.3 \mathrm{~d}\right)$ and in the absence of inhibitor $\left(\square ; t_{1 / 2, a p o}=4.5 \mathrm{~d}\right) . b$, Inhibition of protein kinases by $2 \mu \mathrm{M}$ staurosporine prevents the development of metabolic stabilization by stimulation $\left(O ; t_{1 /, \text { app }}=2.7 \mathrm{~d}\right)$; $\square$, Same stimulation protocol, but in the absence of staurosporine, $t_{1 / 2, a p p}=18 \mathrm{~d}$ (same data as in Fig. $1 a$ ). $c$, Activity-induced AChR stabilization does not require de novo protein synthesis. Data show degradation of synaptic AChRs in muscle stimulated for $6 \mathrm{hr}$ in the presence of CHX $(50 \mu \mathrm{g} / \mathrm{ml}) ; t_{1 / 2 a p p}=16.3 \mathrm{~d}$, that is, comparable to that in CHX-free muscles $\left(t_{1 / 2, \text { app }}=18.0 \mathrm{~d}\right)$. 
6h STIMULATION, NO PN
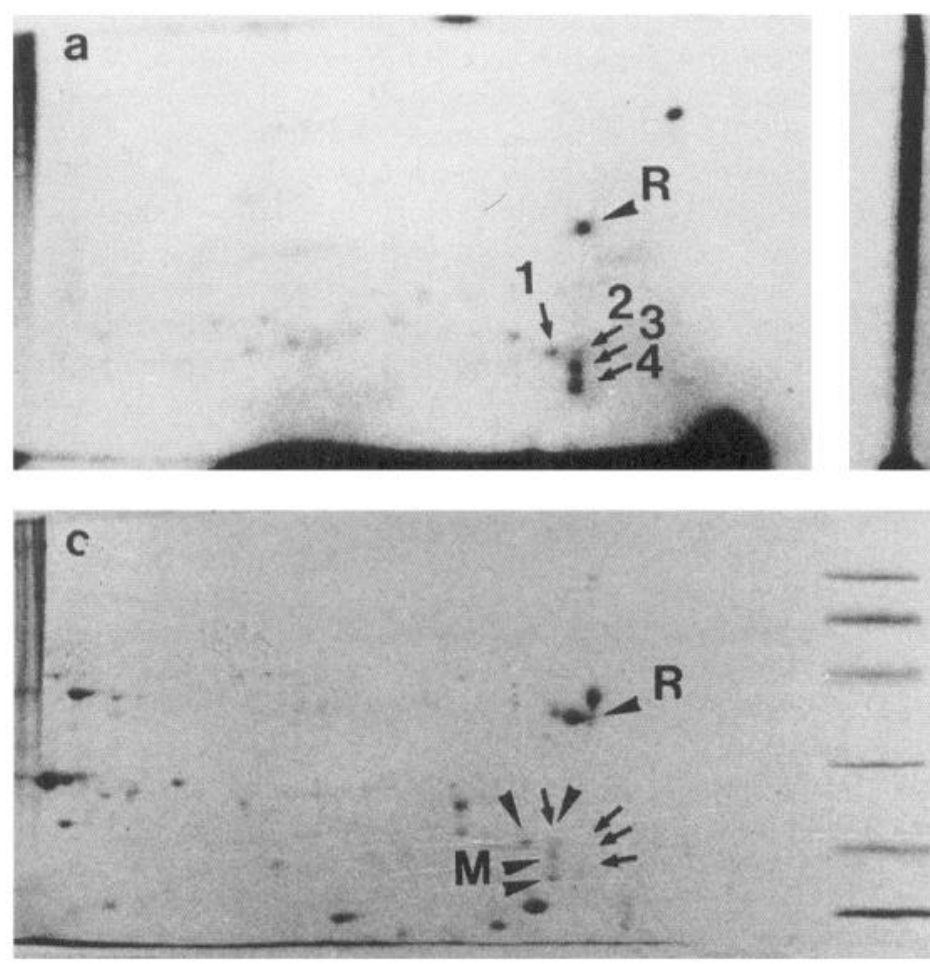

COOMASSIE, 6h ST., NO PN 6h STIMULATION, + PN
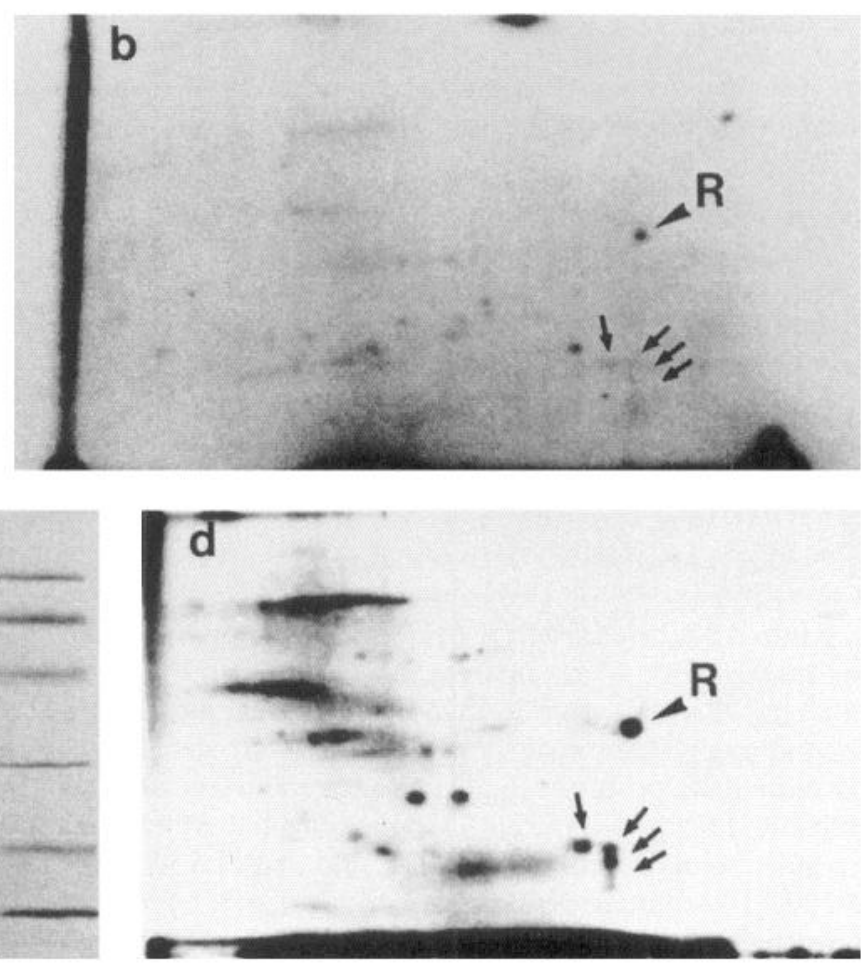

NO STIM., 6h cAMP

Figure 4. Protein phosphorylation during AChR stabilization: (+)PN200-110-sensitive phosphorylation of proteins, possibly MLC isoforms, in electrically stimulated muscle explants. Chronically denervated diaphragm muscle was either stimulated for $6 \mathrm{hr}$ in vitro in the absence $(a)$ or in the presence $(b)$ of $(+) \mathrm{PN} 200-110$, or was incubated for $6 \mathrm{hr}$ in the presence of $0.5 \mathrm{~mm}$ DBcAMP but in the absence of electrical stimulation $(d)$. The incubation conditions in $a$ and $d$ produced AChR stabilization, whereas those in $b$ did not. All incubations were performed in the presence of ${ }^{32} \mathrm{P}$-orthophosphate, and the autoradiogram of two-dimensional gel fractionated proteins (basic $\mathrm{pH}$ to the left) are shown in $a, b, d$; the Coomassiestained proteins of the gel shown in $a$ are shown in $c$. Molecular weight markers to the right of gel $(c)$ are $92,68,45,32,21$, and 14 kDa. A reference ${ }^{32} \mathrm{P}$-species that migrated to a position slightly more acidic than tropomyosin is indicated by $R$ and an arrowhead. In addition, the migration position of some proteins identified by Western blotting is indicated by arrowheads in $c$; these were species stained by monoclonal antibody MY21 , suggesting that they are the fast and slow MLC isoforms (four arrowheads, $M$ ). The Coomassie-stained species can be detected in $c$, and the corresponding phosphoforms, which focused at a slightly more acidic $\mathrm{pH}$, are indicated by the small arrows (these species yielded weak Coomassie signals); numbers in $a$ correspond to P1-P4 as discussed in the text.

ulation pattern, and then left them unstimulated for another 3 $\mathrm{hr}$ before they were labeled with ${ }^{125} \mathrm{I}-\alpha$-BuTX. At this low concentration, okadaic acid has no effect on $\mathrm{Ca}^{2+}$ currents in the heart (Hescheler et al., 1988). The $t_{1 / 2, a p p}$ of the synaptic AChRs was then $6.5 \mathrm{~d}$. In contrast to the AChR half-life in muscles stimulated in the absence of okadaic acid, this was significantly longer than the $t_{1 /, \text { app }}$ of AChRs in unstimulated muscles. The effect of okadaic acid was even greater after $4.5 \mathrm{hr}$ of stimulation when $t_{1 / 2, \text { app }}$ reached $12.2 \mathrm{~d}$ (Fig. $3 a$, Table $1 H$ ). Similar results were obtained when the muscles were treated with $10 \mathrm{~nm}$ calyculin A during the $4.5 \mathrm{hr}$ stimulation period, the $t_{y_{2, \text { app }}}$ of the synaptic AChRs reaching $9.3 \mathrm{~d}$ (Table $1 H$ ). These findings with two different types of phosphatase inhibitors therefore indicate that at least one step in the signaling cascade mediating activitydependent AChR stabilization is the phosphorylation of protein(s).

In agreement with this notion, we found that inhibition of phosphorylation by the blockade of protein kinase activity with $500 \mathrm{nM}$ and $2 \mu \mathrm{M}$ staurosporine prevented the stimulation-induced increase in the metabolic stability of the AChRs. At these concentrations, staurosporine not only blocks protein kinase $\mathrm{C}$ but inhibits other kinases as well (Ruegg and Burgess, 1989). Thus, the $t_{1 / 2, \text { app }}$ of synaptic AChRs in muscles stimulated for 6 $\mathrm{hr}$ in the presence of $500 \mathrm{~nm}$ staurosporine was $4.9 \mathrm{~d}$, which was significantly lower than that in untreated muscles but higher than in nonstimulated muscles. When muscles were treated with $2 \mu \mathrm{M}$ staurosporine, $t_{1 / 2, \text { app }}$ was $2.7 \mathrm{~d}$, that is, comparable to that in muscle stimulated in the presence of $\mathrm{Ca}^{2+}$ channel blockers or in nonstimulated muscle (Fig. $3 b$, Table $1 H$ ).

To test for an involvement of protein synthesis in the stabilization process, we determined whether the blockade of protein synthesis had an effect on AChR stabilization in stimulated muscle. One hour before stimulation was begun, $\mathrm{CHX}(50 \mu \mathrm{g})$ $\mathrm{ml}$ ) was added to the culture medium. Figure $3 c$ shows that activity-induced stabilization of AChRs was not inhibited by $\mathrm{CHX}$, the value of $t_{v_{2, \text { app }}}$ averaging $16.3 \mathrm{~d}$ (Table $1 G$ ). To confirm that $\mathrm{CHX}$ in the concentration added indeed did block protein synthesis, we compared the incorporation of ${ }^{35} \mathrm{~S}$-labeled amino acids into protein extracted from $\mathrm{CHX}$-free and $\mathrm{CHX}$-pretreated muscles. Protein synthesis was 96-99\% blocked (range of different protein species; overall average approximately $98 \%$; data not shown) by $\mathrm{CHX}$ treatment, confirming the efficiency 
of the $\mathrm{CHX}$ concentration used. These experiments indicate that activity-dependent $\mathrm{AChR}$ stabilization is independent of de novo protein synthesis.

\section{Activity-dependent protein phosphorylation with pharmacological properties similar to those of AChR stabilization}

The experiments presented above suggest that $\mathrm{Ca}^{2+}$ influx may cause stabilization by initiating protein phosphorylation reactions. We therefore determined whether (+)PN200-110-sensitive, stimulation-dependent protein phosphorylation could be detected in explants of denervated muscle. One-dimensional SDS-PAGE analysis of proteins phosphorylated in situ in the presence of ${ }^{32} \mathrm{P}$-ATP revealed that phosphoprotein patterns upon a $6 \mathrm{hr}$ stimulation period in the presence or in the absence of (+)PN200-110 were very similar, with the exception of a group of (+)PN200-110-sensitive ${ }^{32} \mathrm{P}$ bands in the 16-20 $\mathrm{kDa}$ range. Upon two-dimensional gel electrophoresis, these proteins were resolved into ${ }^{32} \mathrm{P}$-labeled species of very similar isoelectric point (approximately 4.8), with apparent molecular weights of 16 kDa (P4), 18 kDa (P3), and $20 \mathrm{kDa}$ (P1, P2) (Fig. 4a). Corresponding strongly Coomassie-stained species were detected at slightly more basic positions in the presence and in the absence of (+)PN200-110 (arrows in Fig. 4c), indicating that the proteins corresponded to major species in muscle and that they were not (+)PN200-110-sensitive degradation products. All (+)PN200110-scnsitive species were detected by antibody MY-21 directed against $M L C$ proteins. These observations combined are consistent with the hypothesis that P1-P4 are the phosphoforms of different MLC isoforms. As shown in Figure 4, P1-P4 were the only species whose activity-dependent phosphorylation was clearly prevented by the presence of (+)PN200-110. Close examination of a number of gel pairs as those shown in Figure 4 failed to reveal additional phosphoproteins that were consistently and significantly affected by this treatment. Our findings therefore demonstrate that a (+)PN200-110-sensitive phosphorylation pathway does exist in chronically denervated skeletal muscle in situ. This pathway does not seem to affect phosphorylation of most major muscle phosphoproteins in denervated, electrically stimulated muscle explants.

As demonstrated above, AChR stabilization in vitro could also be achieved upon incubation of chronically denervated muscle explants in the presence of DBc $\Lambda M P$. We therefore analyzed corresponding phosphoproteins in order to search for common aspects of the two stabilization protocols. As shown in Figure $4 d$, phosphorylation of several muscle proteins was elevated in the presence of the cAMP analog, and these included P1, P2, P3, and to a lesser extent P4. Therefore, two different protocols that produced AChR stabilization, muscle stimulation and DBcAMP treatment, were accompanied by the protein phosphorylation.

AChR stabilization in vitro and in vivo required high-frequency electrical stimulation for several hours: as shown in Figure 5, $a$ and $b, \mathrm{Pl}-\mathrm{P} 4$ phosphorylation was only detected upon electrical stimulation of the muscle, irrespective of whether it had been chronically denervated or whether it had been collected from an otherwise untreated animal. In addition, as shown in Figure $5 g$, a low-frequency stimulation protocol that was insufficient to produce $\Lambda \mathrm{ChR}$ stabilization was also little effective in inducing P1-P4 phosphorylation.

The experimental conditions for AChR stabilization were unusual in that de novo protein synthesis was not required and yet stimulation had to be applied for several hours in order to achieve stabilization. Perhaps even more surprising was the finding that once stabilization had been achieved, it lasted for several days in the absence of further stimulation. We therefore determined the time course of P1-P4 phosphorylation during a $100 \mathrm{~Hz}$ stimulation protocol. As shown in Figure 5, $c$ and $d$, $\mathrm{P} 1-\mathrm{P} 4$ phosphorylation was relatively slow in that it was very low after $10 \mathrm{~min}$ of stimulation. On the other hand, saturation appeared to have been reached after $1 \mathrm{hr}$ of stimulation, that is, at a time when no AChR stabilization could yet be detected. Receptor stabilization did therefore not corrclatc in time with saturation of ${ }^{32} \mathrm{P}$ incorporation into P1-P4. Similarly, the persistence of stable AChRs did not correlate with the half-life of phosphorylated P1-P4: as shown in Figure 5, $e$ and $f$, more than $50 \%$ of incorporated phosphate was lost after a 30 min stimulation-free interval, and no label could be detected after a $14 \mathrm{hr}$ resting period. Our findings do not allow to conclude that a causal relation between $\mathrm{P} 1-\mathrm{P} 4$ phosphorylation and AChR stabilization exists, and we cannot exclude that a hypothetical relevant phosphoprotein was too rare to be detected by our experimental conditions. If, on the other hand, P1-P4 phosphorylation should be relevant to the receptor stabilization process, our data would indicate that phosphorylation may be a prerequisite for stabilization, but that, once achieved, a stable receptor configuration would not require the continuous presence of phosphorylated mediator. As discussed in more detail below, such an interpretation may provide a plausible hypothesis to rationalize the properties of the receptor stabilization process.

Finally, we determined whether the $(+)$ PN200-110-sensitive phosphorylation pathway was restricted to the endplate region of the diaphragm. As shown in Figure $5, h$ and $i$, no differences in P1-P4 phosphorylation could be detected between synapsecontaining and synapse-free diaphragm, indicating that the phosphorylation pathway revealed in this study was not unique to the subsynaptic space.

\section{Discussion}

In the present work, we have characterized the signaling pathway linking muscle activity and the metabolic stabilization of synaptic AChRs in rat muscle. Advantage was taken of our previous finding (Rotzler et al., 1991) that AChR stability can be induced by direct stimulation at chronically denervated cndplates of organ cultured muscle.

Culturing the muscles allowed experimental manipulations that are not possible in vivo, but one limitation of this approach was that, in order to ensure viability of the muscles during the entire culturing period, the maximal culturing time was restricted to $4 \mathrm{~d}$. This is short compared to the well known half-life of metabolically stable AChRs, which is $>10 \mathrm{~d}$. As a consequence, changes in $t_{1 / 2, a p p}$ as defined here did not allow us to distinguish between a gradual change in the half-life of a single population of AChRs with uniform stabilities as opposed to a change in the proportion of multiple populations of $\mathrm{AChRs}$ with different half-lives. In fact, even in innervated muscle, AChRs with different stabilities exist (Stanley and Drachman, 1983), and two populations of low-stability synaptic AChRs with $t_{1 / 2}$ of 3 and about $1 \mathrm{~d}$, respectively, have been observed in chronically denervated mouse sternomastoid muscle labcled in vivo (Shyng and Salpeter, 1990; Shyng et al., 1991). In the context of the present study, however, the term "stabilization" indicates a significant difference in $t_{1 / 2, \text { app }}$ of synaptic AChRs in treated versus 


\section{DEN,NON ST. $\quad$ CON,NON ST. 10 MIN STIM.}

\section{1h STIM.}
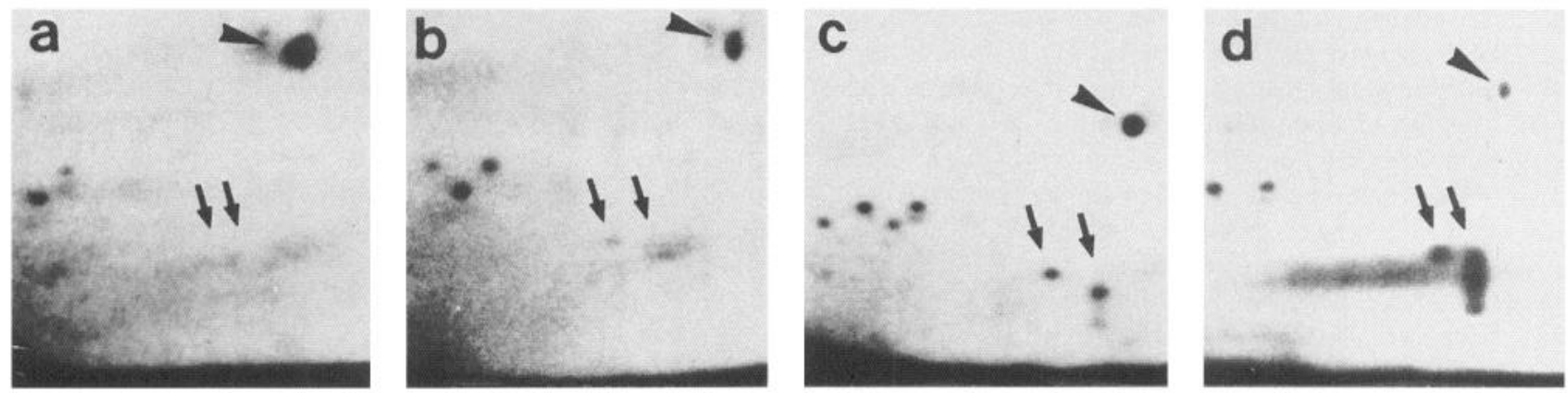

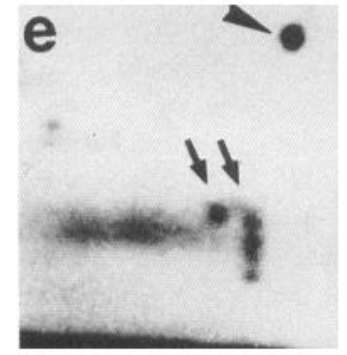

30 MIN CH.

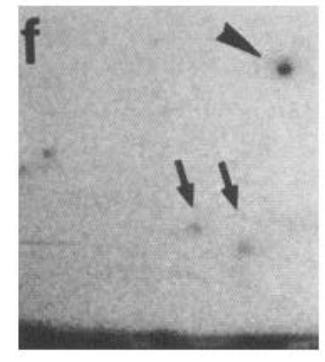

$14 \mathrm{~h} \mathrm{CH}$.

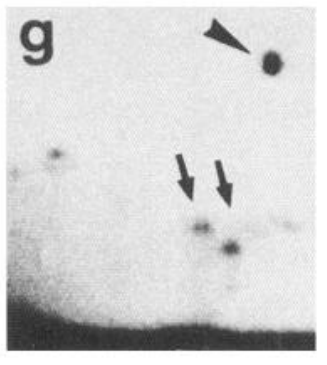

LOW FREQ.

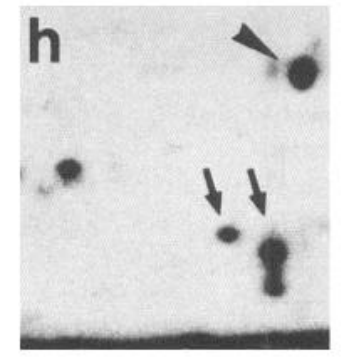

SYN.

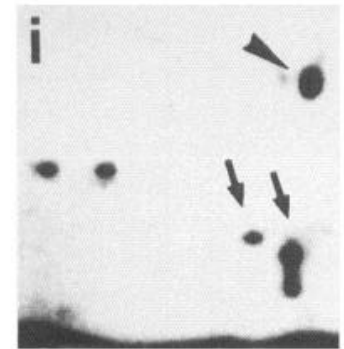

NON-SYN.

Figure 5. Activity-dependent phosphorylation in diaphragm explants: requirement for high-frequency electrical stimulation and kinetics of phospho- and dephosphorylation. $a$ and $b$, Absence of P1-P4 phosphorylation in nonstimulated explants, irrespective of whether these were from chronically denervated $(a)$ or innervated $(b)$ muscle. $c$ and $d$, Time course of P1-P4 phosphorylation. High-frequency $(100 \mathrm{~Hz})$ stimulation of chronically denervated muscle was applied for $10 \mathrm{~min}(c)$ or $1 \mathrm{hr}(d)$ prior to protein fractionation. P1-P4 phosphorylation was relatively slow: 10 min of stimulation only produced a minor reaction, whereas phosphorylation patterns after $1 \mathrm{hr}(d)$ and $6 \mathrm{hr}(h, i)$ were comparable. $e$ and $f$, Dephosphorylation of P1-P4 in the absence of electrical stimulation. Explants were stimulated for $6 \mathrm{hr}$ and then further incubated for 30 min $(e)$ or $14 \mathrm{hr}(f)$ in the absence of stimulation. The $30 \mathrm{~min}$ chase period resulted in an approximately $50 \%$ reduction in incorporated ${ }^{32} \mathrm{P}$, while essentially all label had been removed after a period of $14 \mathrm{hr}$. $g$, Low-frequency stimulation $(20 \mathrm{~Hz})$ for $6 \mathrm{hr}$, which does not produce AChR stabilization, is also little effective in inducing phosphorylation of $\mathrm{P} 1-\mathrm{P} 4 . h$ and $i$, Comparable phosphorylation of P1-P4 in the synaptic $(h)$ and nonsynpatic $(i)$ region of chronically denervated diaphragm stimulated for $6 \mathrm{hr}$. Arrowheads, reference ${ }^{32} \mathrm{P}$-species as in Figure 4; arrows, approximate migration positions of P1 and P2. Only P1-P4-containing details of two-dimensional gel autoradiograms like those shown in Figure 4 are shown in the figure.

those in untreated control muscles, assuming uniform $\mathrm{AChR}$ stability.

\section{Muscle stimulation causes stabilization of synaptic AChRs inserted after denervation}

In denervated mouse muscle, the subpopulation of synaptic AChRs with the $t_{1 / 2}$ of $1 \mathrm{~d}$ could not be restabilized, either by reinnervation or by DBcAMP treatment. These AChRs are thought to have been incorporated into the endplate membrane after the removal of the nerve (Shyng and Salpeter, 1990; Shyng et al., 1991). In the present work on rat soleus muscle, however, we could not resolve synaptic AChRs resisting stabilization whether it was induced by stimulation or by treatment with cAMP. After $17 \mathrm{~d}$ of denervation, as little as $6 \mathrm{hr}$ of highfrequency stimulation or $24 \mathrm{hr}$ of cAMP treatment was sufficient for complete stabilization of synaptic AChRs, and most of these were stabilized after they had been incorporated into the synaptic membrane. This follows from Bevan and Steinbach (1983, their Fig. $10 B$ ), who showed that rat soleus endplates at $14 \mathrm{~d}$ postdenervation contain only about $25 \%$ of the original AChRs that were present at the time of denervation. Consequently, since the total number of $\mathrm{AChRs}$ remains unchanged within the same time (Frank et al., 1976), 75\% of the synaptic AChRs present at $14 \mathrm{~d}$ postdenervation must have been inserted after the denervation, and were subsequently metabolically stabilized by stimulation or cAMP. At 40 d of denervation when stimulation also caused stabilization, this percentage was even higher. Thus, at chronically denervated rat soleus endplates, we have obtained no evidence for the presence of a sizable population of synaptic AChRs that would resist stabilization and have a $t_{1 / 2}$ comparable to that of extrasynaptic AChRs. The reason for the discrepancy to the mouse is not clear. It could not be due to damage of the cultured muscles by stimulation, since we obtained similar results in muscles stimulated in vivo. Another possibility is a species difference, as mouse endplates are less resistant to denervation in their structure than rat endplates (Brown et al., 1982).

AChR stabilization by stimulation was critically dependent on the stimulation pattern used in that a minimum of $6 \mathrm{hr}$ of $100 \mathrm{~Hz}$ trains of $1 \mathrm{sec}$ duration applied once per $100 \mathrm{sec}$ was required; shorter trains, shorter stimulation times, or lower frequencies even with a higher number of stimuli were not effective. Recently, Fumagalli et al. (1992) have reported that $100 \mathrm{~Hz}$ trains containing 60 pulses applied to rat soleus muscle in vivo were ineffective even when applied for several days.

Activity-dependent AChR stabilization is mediated by $\mathrm{Ca}^{2+}$ influx through sarcolemmal $\mathrm{Ca}^{2+}$ channels

The blockade of activity-induced AChR stabilization by the $\mathrm{Ca}^{2+}$ channel blockers (+)PN200-110 and D600, on the one hand, and its induction in the absence of stimulation by the 
$\mathrm{Ca}^{2+}$ channel activator $(+) \mathrm{SDZ} 202-791$, on the other, demonstrate that stabilization is mediated by $\mathrm{Ca}^{2+}$ entering the muscle fiber through voltage-activated membrane channels (Rotzler et al., 1991). In the heart, (+)PN200-110 and D600 are known to block the slowly activating L-type $\mathrm{Ca}^{2+}$ current. In skeletal muscle, (+)PN200-110 blocks a related current, $I_{\text {slow }}$, which is also elicited by repetitive brief depolarizations such as trains of action potentials (Rotzler et al., 1991). In contrast, (+)SDZ202791 prolongs the opcnings of cardiac L-type channels (Kokubun et al., 1986), suggesting that in our experiments, it increased transmembrane $\mathrm{Ca}^{2+}$ currents by prolonging the openings of channels activated by $\mathrm{K}^{+}$-induced depolarization. Thus, blockade of $I_{\text {slow }}$ blocks AChR stabilization while its selective activation promotes it.

In contrast, the $\mathrm{Ca}^{2+}$ released from the $\mathrm{SR}$ during excitationcontraction coupling does not appear to be involved in AChR stabilization, suggesting that it is sequestered before it reaches sites relevant for $\mathrm{Ca}^{2+}$-dependent $\mathrm{AChR}$ stabilization near the muscle fiber membrane. Likewise, no evidence for a role of $\mathrm{Ca}^{2+}$ entering through endplate AChR channels was found: AChR stabilization induced by nerve stimulation was prevented by (+)PN200-110. Therefore, since mammalian motor nerve terminals do not contain DHP-sensitive $\mathrm{Ca}^{2+}$ channels (Penner and Dreyer, 1986; Uchitel et al., 1992), and, consequently, ACh relcase from nerve terminals would not be affected by DHPs, it appears that $\mathrm{Ca}^{2+}$ entry through endplate $\mathrm{AChR}$ channels during impulse transmission was not sufficient for stabilizing the AChRs. This seems surprising, since a substantial fraction of the endplate current was recently shown to be carried by $\mathrm{Ca}^{2+}$, which could lead to a significant increase in free $\mathrm{Ca}^{2+}$ below the endplate membrane (Decker and Dani, 1990). Possibly, DHP-sensitive $\mathrm{Ca}^{2+}$ channels are concentrated in the endplate region as are other voltage activated types of ion channels (Caldwell et al., 1986; Flucher and Daniels, 1989) or $\mathrm{Ca}^{2+}$ entering through AChR channels may be sequestered before it reaches the sites relevant for the stabilization process.

In an earlier study by Shyng et al. (1991), it was demonstrated that DBcAMP can stabilize AChRs of mouse sternomastoid muscle in the absence of activity. We found that DBcAMP in the absence of muscle activity stabilizes the synaptic AChRs in rat soleus muscle. However, we could not detect an effect of stimulation on cAMP levels, even in endplate-enriched muscle segments. Since, on the other hand, muscle activity may have caused a focal increase in subsynaptic cAMP so restricted as to escape detection, an involvement of cAMP in activity-induced AChR stabilization cannot be excluded at this time.

With $\mathrm{Ca}^{2+}$ influx postulated to mediate AChR stabilization, the possibility of $\mathrm{Ca}^{2+}$-activated neutral proteases causing generalized muscle damage that could have produced decreased metabolic rates must be considered. For example, morphological damage has been observed in nerve-stimulated muscle after blockade of $\mathrm{AChE}$, which was thought to be caused by excessive $\mathrm{Ca}^{2+}$ influx through endplate channels (Leonard and Salpeter, 1979). We have therefore examined the ultrastructure of denervated muscles stimulated in the presence and in the absence of (+)PN200-110 (W. Rudin and H. R. Brenner, unpublished obscrvation). No difference in ultrastructure could be resolved between unblocked muscle and muscle blocked by (+)PN200110 where AChR stabilization did not occur. Specifically, no increase in large-diameter vesicles in the soleplasm, dilation of mitochondria, or destruction of SR could be observed as has been reported in the vicinity of AChE-blocked endplates (Leonard and Salpeter, 1979). Thus, whatever damage might have occurred, it did not appear to be related to the increased stability of the endplate AChRs.

\section{Signaling pathways for AChR stabilization}

Stabilization of junctional AChRs appears to require an elevated concentration of free $\mathrm{Ca}^{2+}$ in the subsarcolemmal space for at least $6 \mathrm{hr}$, since rapid stabilization depended on the pattern rather than on the amount of stimulation applied. No significant stabilization was detected after $3 \mathrm{hr}$ of stimulation, and marginal stabilization was achieved after $4.5 \mathrm{hr}$ of stimulation. Surprisingly, in spite of its comparatively long duration, the stabilization process did not depend on de novo protein synthesis, as demonstrated by its insensitivity to $\mathrm{CHX}$. Under our experimental conditions, $\mathrm{CHX}$ reduced protein synthesis in muscle explants to less than $2 \%$ of control. Inhibition may have been even more complete in the muscle fibers on the surface of the explant, which have been used for assessing AChR stability. Thus, activity-dependent activation of genes, either by the synthesis of new or by the posttranslational modification of preexisting regulatory factors, does not play a role in the AChR stabilization. Rather, our data indicate that $\mathrm{Ca}^{2+}$-dependent reactions in the muscle fibers initiate posttranslational modifications of preexisting components, leading to a metabolically stable AChR configuration. The establishment of this configuration requires approximately $6 \mathrm{hr}$ of elevated intramuscular $\mathrm{Ca}^{2+}$, and the configuration is then stable for several days in the absence of activity.

Phosphorylation is likely to be involved in the stabilization process: this is suggested by the stabilizing effect of DBcAMP in the absence of stimulation, by its sensitivity to $2 \mu \mathrm{M}$ staurosporine and by the reduction in the minimal amount of activity required to produce stabilization in the presence of the inhibitors of protein phosphatases, okadaic acid (Bialojan and Takai, 1988) or calyculin A (Ishihara et al., 1989), from $6 \mathrm{hr}$ to 3-4.5 hr. The simplest interpretation of the latter findings is that these compounds blocked the dephosphorylation of a protein that had been phosphorylated following activity-dependent $\mathrm{Ca}^{2+}$ influx and whose continued presence in its phosphorylated state is necessary for AChR stabilization.

The demonstration of a DHP-sensitive phosphorylation pathway in the explant system is consistent with the idea that phosphorylation is involved in the DHP-sensitive stabilization process. Like stabilization, the DHP-sensitive phosphorylation was dependent on high-frequency stimulation. On the other hand, maximal phosphorylation was already detected after $1 \mathrm{hr}$ of stimulation, suggesting that if DHP-sensitive substrates like MLC are indeed involved in AChR stabilization, downstream events were rate limiting in this process. In summary, therefore, our data are consistent with a model proposing that activity-dependent $\mathrm{Ca}^{2+}$ influx through the sarcolemma would activate a specific protein phosphorylation pathway producing components essential for the establishment of the stable AChR configuration at the synapse. Stabilization itself would be a comparatively slow process $(6 \mathrm{hr})$ that would require the presence of the activity-dependent component during its entire progress.

What molecular mechanisms may be operating to stabilize synaptic AChRs? Metabolic stability of AChRs may be controlled by direct nerve-dependent posttranslational modifications or their state of association with anchoring sites enriched in the endplate membrane or its fibrous substructure (Salpeter, 1987). Various cytoskeletal proteins including myosin are associated with the endplate membrane (for reviews, see Bloch and Pumplin, 1988; Froehner, 1991). Although our data do not 
imply a relation between MLC phosphorylation and AChR stabilization, they are consistent with the involvement of $\mathrm{Ca}^{2+}$ dependent phosphorylation of cytoskeletal components, possibly MLCs, in the stabilization process. It is conceivable that this reaction may initiate myosin-mediated structural changes in the endplate region. Nonsarcomeric myosin requires phosphorylation of MLCs for activation (Trybur, 1989), and may in turn produce changes in cytoskeletal structures between the subsynaptic biosynthetic apparatus and junctional AChRs. Such structural modifications may be slow to establish but very stable, thus contributing to the persistence of metabolically stable AChRs in activity-deprived muscle. In terms of this hypothesis, the presence of MLC along the entire length of the muscle fiber could account for the high metabolic stability observed recently not only in synaptic but also in extrasynaptic AChRs present in normally innervated mouse soleus muscle (Salpeter and Marchaterre, 1992).

\section{References}

Avila OL, Drachman DB, Pestronk A (1989) Neurotransmission regulates stability of acetylcholine receptors at the neuromuscular junction. I Neurosci 9:2902-2906.

Bevan S, Steinbach JH (1983) Denervation increases the degradation rate of rat acetylcholine receptors at endplates in vivo and in vitro. J Physiol (Lond) 336:158-177.

Bialojan C, Takai A (1988) Inhibitory effect of a marine sponge toxin, okadaic acid, on protein phosphatases. Biochem J 256:283-290.

Bloch RJ, Pumplin DW (1988) Molecular events in synaptogenesis: nerve-muscle adhesion and postsynaptic differentiation. Am J Physiol 254:C345-C364.

Boivin P (1988) Role of the phosphorylation of red blood cell membrane proteins. Biochem J 256:689-695.

Brenner HR, Rudin W (1989) On the effect of muscle activity on the end-plate membrane in denervated mouse muscle. J Physiol (Lond) 410:501-512.

Brenner HR, Iamo T, Williamson R (1987) Control of end-plate channel properties by neurotrophic effects and muscle activity in rat. J Physiol (Lond) 410:501-512.

Brett RS, Younkin SG, Konieczkowski M, Slugg RM (1982) Accelerated degradation of junctional acetylcholine receptor- $\alpha$-bungarotoxin complexes in denervated rat diaphragm. Brain Res 233:133142.

Brown MC, Hopkins WG, Keynes RJ, White I (1982) A comparison of early morphological changes at denervated and paralyzed endplates in fast and slow muscles of the mouse. Brain Res 248:382-386.

Caldwell J, Campbell D, Beam K (1986) Na channel distribution in vertebrate skeletal muscle. J Gen Physiol 87:907-932.

Decker ER, Dani JA (1990) Calcium permeability of the nicotinic acetylcholine receptor: the single channel calcium influx is significant. J Neurossi 10:3413-3420.

Fairhurst AS, Hasselbach W (1970) Calcium efflux from a heavy sarcotubular fraction. Eur J Biochem 13:504-509.

Flucher B, Daniels $P$ (1989) Distribution of $\mathrm{Na}^{+}$channcls and ankyrin in neuromuscular junctions is complementary to that of acetylcholine receptors and the $43 \mathrm{kD}$ protein. Neuron 3:163-175.

Frank E, Gautvik K, Sommerschild H (1976) Cholinergic receptors at denervated mammalian motor endplates. Acta Physiol Scand 95: 66-76.

Froehner SC (1991) The submembrane machinery for nicotinic acetylcholine receptor clustering. J Cell Biol 114:1-7.

Fumagalli G, Balbi S, Cangiano A, Lømo T (1990) Regulation of turnover and number of acetylcholine receptors at neuromuscular junctions. Neuron 4:563-569.

Fumagalli G, Andreose J, Lamo T, Salpeter MM (1992) Mechanism of activity dependent stabilization of AChR degradation at denervated endplates. J Cell Biochem 16E:232.

Hescheler J, Mieskes G, Rüegg JC, Takai A, Trautwcin W (1988) Effects of a phosphatase inhibitor, okadaic acid, on membrane currents of isolated guinea-pig cardiac myocytes. Pfluegers Arch 312:248-252.

Ishihara $\mathrm{H}$, Martin BL, Brautigan DL, Karaki H, Ozaki H, Kato Y,
Fusetani N, Watabe S, Hasimoto K, Uemera D, Hartshorene DJ (1989) Calyculin A and okadaic acid: inhibitors of protein phosphatase activity. Biochem Biophys Res Commun 159:871-877.

Jasmin BJ, Changeux J-P, Cartaud J (1990) Compartmentalization of cold-stable and acetylated microtubules in the subsynaptic domain of chick skeletal muscle fiber. Nature 344:673-675.

Kokubun S, Prod'hom B, Becker C, Porzig H, Reuter H (1986) Studies on $\mathrm{Ca}$ channels in intact cardiac cells: voltage-dependent effects and cooperative interactions of dihydropyridine enantiomers. Mol Pharmacol 30:571-584.

Laemmli UK (1970) Cleavage of structural proteins during the assembly of the head of bacteriophage T4. Nature 227:680-685.

Leonard JP, Salpeter MM (1979) Agonist-induced myopathy at the neuromuscular junction is mediated by calcium. J Cell Biol 82:811819

Lomo T, Massoulie M, Vigny M (1985) Stimulation of denervated rat soleus muscles with fast and slow activity patterns induces different expression of acetylcholinesterase molecular forms. J Neurosci 5:1 1801187.

Loring R, Salpeter MM (1980) Denervation increases turnover rate of junctional acetylcholine receptors. Proc Natl Acad Sci USA 77:22932298.

Miledi R, Parker I, Schalow G (1980) Transmitter induced calcium entry across the post-synaptic membrane at frog end-plates measured using arsenazo III. J Physiol (Lond) 300:197-212.

Nestler EJ, Beam KG, Greengard P (1978) Nicotinic cholinergic stimulation increases cyclic GMP levels in vertebrate skeletal muscle. Nature 275:451-453.

O'Farrell PH (1975) High resolution two-dimensional gel electrophoresis of proteins. J Biol Chem 250:4007-4021.

Penner R, Dreyer F (1986) Two different presynaptic calcium currents in mouse motor nerve terminals. Pfluegers Arch 406:190-197.

Reiness CG, Weinberg CB (1981) Metabolic stabilization of acetylcholine receptors at newly formed neuromuscular junctions. Dev Biol $84: 247-254$.

Rotzler S, Brenner HR (1990) Metabolic stabilization of acetylcholine receptors in vertebrate neuromuscular junction by muscle activity. $\mathrm{J}$ Cell Biol 111:655-661.

Rotzler S, Schramek H, Brenner HR (1991) Metabolic stabilization of endplate acetylcholine receptors regulated by calcium influx associated with muscle activity. Nature 349:337-339.

Ruegg UT, Burgess GM (1989) Staurosporine, K252 and UCN-01: potent but nonspecific inhibitors of protein kinases. Trends Pharmacol Sci 10:218-220.

Salpeter MM (1987) Development and neural control of the neuromuscular junction and of the junctional acetylcholine receptor. In: The vertebrate neuromuscular junction (Salpeter MM, ed), pp 55115. New York: Liss.

Salpeter MM, Loring RH (1985) Nicotinic acetylcholine receptors in vertebrate muscle: properties, distribution and neural control. Progr Neurobiol 25:297-325.

Salpeter MM, Marchaterre M (1992) Acetylcholine receptors in extrajunctional region of muscle have a slow degradation rate. $J$ Neurosci $12: 35-38$.

Salpeter MM, Cooper DL, Levitt-Gilmour T (1986) Degradation rates of acetylcholine receptors can be modified in the postjunctional plasma membrane of the vertebrate neuromuscular junction. J Cell Biol 103:1399-1403.

Shyng S-L, Salpeter MM (1990) Effect of reinnervation on the degradation rate of junctional acetylcholine receptors synthesized in denervated skeletal muscles. J Neurosci 10:3905-3915.

Shyng S-L, Xu R, Salpeter MM (1991) Cyclic AMP stabilizes the degradation of original junctional acetylcholine receptors in denervated muscle. Neuron 6:469-475.

Stanley EF, Drachman DB (1981) Denervation accelerates the degradation of junctional acetylcholine receptors. Exp Neurol 73:390396.

Stanley EF, Drachman DB (1983) Rapid degradation of "new" acetylcholine receptors at neuromuscular junctions. Science 222:67-69.

Trybur KM (1989) Filamentous smooth muscle myosin is regulated by phosphorylation. J Cell Biol 109:2887-2894.

Uchitel OD, Protti DA, Sanchez V, Cherkskey BD, Sugimori M, Llinas $R$ (1992) P-type voltage-dependent calcium channel mediates presynaptic calcium influx and transmitter release in mammalian synapses. Proc Natl Acad Sci USA 89:3330-3333. 